\title{
Elevated level of serum carbohydrate antigen 19.9 as predictor of mortality in patients with advanced medullary thyroid cancer
}

\author{
Rossella Elisei ${ }^{1}$, Loredana Lorusso ${ }^{1}$, Paolo Piaggi ${ }^{1}$, Liborio Torregrossa ${ }^{2}$, \\ Giovanni Pellegrini ${ }^{3}$, Eleonora Molinaro', Laura Agate', Valeria Bottici ${ }^{1}$, \\ Fabiana Pani ${ }^{1}$, Andrea Cacciato Insilla ${ }^{2}$, Francesca Casella', Raffaele Ciampi ${ }^{1}$, \\ Ilaria Tognetti ${ }^{3}$, Gabriele Materazzi ${ }^{2}$, Fulvio Basolo ${ }^{2}$ and Cristina Romei ${ }^{1}$ \\ ${ }^{1}$ Endocrine Unit, Department of Clinical and Experimental Medicine and ${ }^{2}$ Department of Surgical, \\ Medical, Molecular Pathology, University of Pisa, Pisa, Italy and ${ }^{3}$ Clinical Chemistry Laboratory, \\ Azienda Ospedaliero-Universitaria Pisana, Pisa, Italy
}

\author{
Correspondence \\ should be addressed \\ to R Elisei \\ Email \\ rossella.elisei@med.unipi.it
}

\begin{abstract}
Background: Medullary thyroid cancer (MTC) is capable of secreting several proteins, such as calcitonin (Ct), carcinoembryonic antigen (CEA), chromogranin and others. Recently, we observed an aggressive MTC with high levels of serum carbohydrate antigen 19.9 (Ca 19.9) and a rapid evolution to death.

Objective: The aim of this study was to evaluate whether high levels of serum Ca 19.9 could be a prognostic factor of death in patients with advanced MTC.

Patients and methods: We measured Ca 19.9, CEA and Ct in 100 advanced structural recurrent/persistent MTC patients and in 100 cured or biochemically affected MTC patients. Clinical and pathological data were also collected.

Results: Sixteen percent of the patients with advanced MTC had high levels of Ca 19.9. The group with abnormal Ca 19.9 levels had significantly higher levels of CEA and Ct compared with the group with normal values of Ca 19.9 ( $P<0.0001$ for both Ct and CEA). At variance, all 100 patients in the MTC control group showed normal levels of Ca 19.9. Moreover, among the advanced cases, the Ca 19.9-positive group showed a higher mortality rate than the group with normal levels. A logistic regression analysis demonstrated that an elevated level of Ca 19.9 is a predictor of mortality $(O R=3.78, P=0.04)$, independent from Ct doubling time.

Conclusions: These results demonstrated that an elevated value of serum Ca 19.9 appears to be a predictive factor of poor prognosis in advanced MTC patients and identifies those cases with a higher risk of mortality in the short term.

\section{Introduction}

Medullary thyroid carcinoma (MTC) is a neoplasia derived from the parafollicular C-cell of the thyroid and accounts for $1-2 \%$ of thyroid malignancies $(1,2,3)$. MTC can occur sporadically (70-80\% of the cases) or as part of the MEN2 syndrome $(20-30 \%$ of the cases) $(4,5)$.

The prognosis of MTC is usually considered to be intermediate between well-differentiated and anaplastic thyroid cancer. Many studies have been published about the clinical and pathological features that can predict the prognosis of MTC patients. Advanced age at diagnosis, advanced stage of the disease and, in particular, the presence of distant metastasis at the time of diagnosis have been found to be correlated with a worse prognosis $(6,7,8,9)$. RE-arranged during transfection (RET) somatic

Published by Bioscientifica Ltd. 
mutations, which are present in $40-50 \%$ of sporadic MTC patients, have also been recognized as a poor prognostic factor for the outcome of these patients $(10,11,12,13)$.

In addition to an advanced age and stage at diagnosis, it is well established that important information about the MTC patients' outcome can be derived from serum calcitonin (Ct) and carcinoembryonic antigen (CEA) levels (14). In particular, the doubling time (Dt) of both $\mathrm{Ct}$ (Ct Dt) and CEA is a strong prognostic indicator for MTC recurrence and death $(15,16,17,18)$.

Other than Ct and CEA, MTC is able to produce several hormonal and non-hormonal substances in the tumor tissue, including calcitonin gene-related peptide (CGRP), neuron- specific enolase (NSE), somatostatin (SRIF) and thyroglobulin (Tg). Some of these markers, but not all, are also detectable in the serum. The production of these proteins, in particular SRIF, seems to be correlated with a higher survival of MTC patients $(19,20)$.

Conversely, there are scarce data on other putative serum tumor markers, such as the gastrointestinal cancer marker carbohydrate antigen 19.9 (Ca 19.9), which has been observed in the tissue of $\sim 6 \%$ of MTC patients (21). Recently, the case of a 56-year-old woman with MEN2B and high serum levels of Ca 19.9 and the case of a young man with MEN2A who exhibited high and progressively increasing serum levels of Ca 19.9 have been reported $(22,23)$ and the possibility that high levels of serum Ca 19.9 could be a prognostic factor of poor prognosis has been suggested.

Based on these last observations, we performed the present study to verify whether high serum levels of $\mathrm{Ca}$ 19.9 could be a predictive factor of poor prognosis in patients with advanced MTC and to analyze whether there was any correlation with the serum Ct and CEA levels and with the Ct Dt.

\section{Patients and methods}

\section{Study group}

We studied 100 consecutive patients (41 females (41\%), 59 males (59\%)) with an advanced structural persistent/ recurrent MTC (i.e., presence of local disease and/or metastatic lymph node and/or distant metastases) at the time of the observation and who underwent a clinical control at the Endocrine Unit of the Department of Clinical and Experimental Medicine of Pisa University between 2011 and 2012. The mean age at diagnosis of the study group was $46+14$ years (range: $13-78$ years; median age: 45.5 years), while the mean age at the time of observation was $53.8+13.9$ years (range: $21-87$ years; median age: 54.5 years).

Eighty-one out of 100 patients underwent near-total thyroidectomy, central compartment lymph node dissection and lateral lymphadenectomy (21 right lymphadenectomy, 23 left lymphadenectomy and 37 bilateral dissections). Fourteen patients underwent near-total thyroidectomy and central compartment lymph node dissection while only five patients underwent near-total thyroidectomy alone. The mean time from the first surgical treatment and the Ca 19.9 determination was $9.7+7.5$ years.

At the time of our observation, $17 \%$ of the patients had lymph node metastases, $68 \%$ had both lymph node metastases and distant metastasis and $15 \%$ had only distant metastases, while at the time of diagnosis $61 \%$ of the patients had lymph node metastases, $28 \%$ had both lymph node and distant metastases and 11\% had no metastases (Table 1).

As controls, Ca 19.9 positivity was measured in 100 MTC patients (50 males, 50 females) who were either cured or with detectable basal Ct without evidence of structural disease (biochemical disease).

The study was approved by the Institutional Reviewing Board and all patients gave consent to participate in the study.

\section{Clinical procedures}

MTC patients underwent biochemical evaluation, which included Ct (ELSA-hCT, CIS, Gif-Sur-Yvette, France; normal range: $<10 \mathrm{pg} / \mathrm{ml}$ ), CEA (ELECSYS CEA, Roche Diagnostics; normal range: $<5.2 \mathrm{ng} / \mathrm{ml}$ ) and $\mathrm{Ca} 19.9$ (ELECSYS CA 19.9 Roche Diagnostics; normal range $<37 \mathrm{U} / \mathrm{ml}$ ). The same laboratories and the same assays were used for the Ct, CEA and Ca 19.9 measurements during the study. We collected and stored the serum from the study groups and the $\mathrm{Ca} 19.9$ measurement was performed at a later time.

Table 1 Type of metastases in advanced MTC patients at the time of diagnosis and at the time of our observation when the serum Ca 19.9 was measured.

\begin{tabular}{|c|c|c|c|c|}
\hline & \multicolumn{4}{|c|}{ Type of metastases } \\
\hline & $\begin{array}{l}\text { Lymph } \\
\text { node }(\%)\end{array}$ & Distant (\%) & $\begin{array}{l}\text { Both lymph } \\
\text { node and } \\
\text { distant }(\%)\end{array}$ & None $(\%)$ \\
\hline $\begin{array}{l}\text { At the time of } \\
\text { diagnosis }\end{array}$ & $61 / 100(61)$ & $0 / 100$ & $28 / 100(28)$ & $11 / 100(11)$ \\
\hline $\begin{array}{c}\text { At the time of } \\
\text { observation }\end{array}$ & $17 / 100$ (17) & $15 / 100$ (15) & $68 / 100(68)$ & $0 / 100$ \\
\hline
\end{tabular}



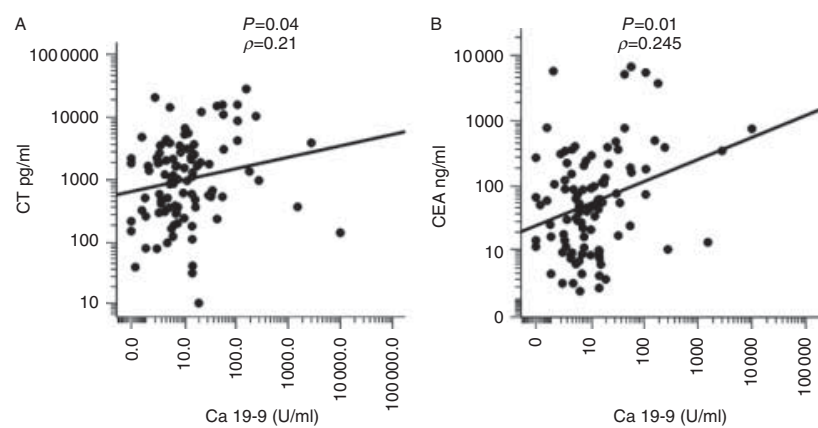

Figure 1

Positive linear correlation between the serum levels of $\mathrm{Ct}$ $(\rho=0.21 ; P=0.04)(\mathrm{A})$ and CEA $(\rho=0.245 ; P=0.01)$ (B) with Ca 19.9 serum values.

Ct Dt was calculated according to the American Thyroid Association (ATA) guidelines (24). In particular, we used the ATA website (http://www.thyroid.org/ thyroid-physicians-professionals/calculators/thyroidcancer-carcinoma/) by reporting at least four serum $\mathrm{Ct}$ values spread over a 2-year period that included the time of Ca 19.9 measurement.

\section{Immunohistochemistry in advanced MTC patients}

Immunohistochemical analysis was performed on 55 tissues (34 primary and 21 metastatic tissue samples) available among the MTC advanced cases $(n=100)$.

All immunohistochemical analyses were performed on archival formalin-fixed and paraffin-embedded specimens using the Ventana Benchmark automatic immunostaining system (Ventana Medical Systems, Tucson, AZ, USA). Paraffin sections (3-5 $\mu \mathrm{m})$ were dewaxed in xylene, dehydrated through graded alcohols and processed using an UltraView DAB detection system (Ventana), following the manufacturer's instructions. Immunostaining was performed using a rabbit polyclonal antibody for $\mathrm{Ct}$ and mouse MABs for chromogranin A and Ca 19.9. Positive controls were always used and constituted by samples of MTC for $\mathrm{Ct}$, pancreatic tissue for chromogranin A and colon tissue for Ca 19.9, following the manufacturer's instruction. All of the reagents described above were used for the negative controls, except the primary antibody.

\section{RET genetic screening in advanced MTC patients}

Germline RET mutations were analyzed in all 100 advanced MTC cases while RET somatic mutations were analyzed in 57 patients. Genomic DNA was purified from peripheral blood lymphocytes and from fresh or paraffin embedded tumoral tissues as previously described for the identification of somatic RET mutations (19). Sequence analysis of exons 10,11,13, 14, 15 and 16 was performed using the direct Sanger Method following the previously reported protocol (25).

\section{Statistical analysis}

The $\chi^{2}$ test was used for evaluating differences in counts and frequency while the Kolmogorov-Smirnov test was used to assess normality of data. The logarithmic transformation was applied to skewed distributions to approximate a normal distribution. Spearman's $(\rho)$ correlation coefficient was employed to quantify the associations between Ca 19.9 levels and Ct and CEA. Simple and multiple logistic regression analyses were conducted for evaluating the effect of Ca 19.9 and Ct Dt on tumor-related mortality. Survival curves for mortality were calculated using the Kaplan-Meier method and the statistical significance between $\mathrm{Ca} 19.9$ positive and negative groups was assessed using the log-rank test.

A $P$ value $<0.05$ was considered significant. Data are presented as mean \pm s.D. or median with interquartile range (IQR). Analyses were performed using SPSS (Version 21, IBM Corp., Armonk, NY, USA).

\section{Results}

\section{Correlation of serum levels of Ca 19.9 and other MTC serum markers}

Sixteen out of 100 MTC patients with advanced structural recurrent/persistent disease (16\%) showed abnormal serum levels of $\mathrm{Ca} 19.9$ with a mean

Table 2 Comparison of lymph node and distant metastases at the time of our observation in the two groups of structurally persistent/recurrent MTC patients with normal and abnormal levels of serum Ca 19.9 .

\begin{tabular}{|c|c|c|c|}
\hline $\begin{array}{l}\text { Type of } \\
\text { metastases }\end{array}$ & $\begin{array}{c}\text { Ca 19.9-positive } \\
\text { patients }(\%)\end{array}$ & $\begin{array}{c}\text { Ca } 19.9-\text {-negative } \\
\text { patients }(\%)\end{array}$ & $P$ value \\
\hline $\begin{array}{l}\text { Lymph node } \\
\text { metastases }\end{array}$ & $13 / 16(81)$ & $71 / 84(84)$ & 0.7 \\
\hline $\begin{array}{l}\text { Distant metastases } \\
\quad \text { (all) }\end{array}$ & $16 / 16(100)$ & $66 / 84(78)$ & 0.04 \\
\hline Bone metastases & $5 / 16(31)$ & $10 / 84(11)$ & 0.03 \\
\hline Lung metastases & $10 / 16(62)$ & $37 / 84(44)$ & 0.17 \\
\hline Liver metastases & $12 / 16(75)$ & $39 / 84(46)$ & 0.03 \\
\hline
\end{tabular}


Table 3 Clinical and biochemical characteristics of the patients with serum Ca19.9 positivity.

\begin{tabular}{|c|c|c|c|c|c|}
\hline Patient & $\begin{array}{c}\text { Age at } \\
\text { diagnosis }\end{array}$ & $\begin{array}{c}\text { Ca } 19.9 \\
\text { values } \\
(\mathrm{U} / \mathrm{ml})\end{array}$ & $\begin{array}{c}\text { Ct } \\
\text { values } \\
(\mathrm{pg} / \mathrm{ml})\end{array}$ & $\begin{array}{c}\text { CEA } \\
\text { values } \\
(\mathrm{ng} / \mathrm{ml})\end{array}$ & $\begin{array}{c}\text { Ct Dt } \\
\text { (months) }\end{array}$ \\
\hline 1 & 51 & 43 & 239 & 777 & $<6$ \\
\hline 2 & 30 & 158 & 28100 & 500 & $>6$ \\
\hline 3 & 37 & 1527 & 373 & 13 & $<6$ \\
\hline 4 & 25 & 43 & 15000 & 5151 & $<6$ \\
\hline 5 & 28 & 10000 & 144 & 758 & $>6$ \\
\hline 6 & 38 & 243 & 10330 & 392 & $<6$ \\
\hline 7 & 71 & 58 & 3070 & 163 & $>6$ \\
\hline 8 & 54 & 108 & 8730 & 183 & $<6$ \\
\hline 9 & 41 & 181 & 1370 & 3742 & $>6$ \\
\hline 10 & 50 & 276 & 980 & 10 & $>6$ \\
\hline 11 & 56 & 55 & 540 & 24 & $>6$ \\
\hline 12 & 45 & 55 & 15700 & 192 & $>6$ \\
\hline 13 & 56 & 107 & 4230 & 74 & $>6$ \\
\hline 14 & 63 & 2800 & 3900 & 348 & $>6$ \\
\hline 15 & 59 & 107 & 15763 & 5489 & $>6$ \\
\hline 16 & 35 & 57 & 11000 & 6733 & $>6$ \\
\hline
\end{tabular}

value of $988+2513 \mathrm{U} / \mathrm{ml}$ (median: $107 \mathrm{U} / \mathrm{ml}$; range: $42-10000 \mathrm{U} / \mathrm{ml}$ ). The Ca 19.9-positive patients also showed elevated values of serum Ct and CEA (mean $7466+8030 \mathrm{pg} / \mathrm{ml}$ and $1534+2311 \mathrm{U} / \mathrm{ml}$ respectively); mean values of $\mathrm{Ct}$ and CEA were significantly higher $(P<0.0001$ for both Ct and CEA) in patients with elevated levels of Ca 19.9 than in Ca 19.9 negative patients (mean Ct and CEA values were $1934+3089 \mathrm{pg} / \mathrm{ml}$ and $160+$ $631 \mathrm{U} / \mathrm{ml}$, respectively). A positive correlations between the Ct $(\rho=0.21 ; P=0.04)$ and CEA $(\rho=0.245 ; P=0.01)$ serum values with Ca 19.9 values were found (Fig. 1A and $B$ respectively).

Six out of 100 MTC patients with structural recurrent/persistent disease (6\%) (five Ca 19.9 positive and one Ca 19.9 negative patient) had a Ct Dt $<6$ months, while the other 94 patients (94\%) had a Ct Dt longer than 6 months, including the other ten patients with elevated Ca 19.9 .

Among controls, none of the cured MTC patients nor those with biochemical disease showed elevated levels of serum Ca 19.9.

\section{Correlation of serum levels of Ca 19.9 and clinico-pathological features}

As shown in Table 2, the serum Ca 19.9 levels were statistically significantly associated $(P=0.04)$ with the presence of distant metastases at the time of our observation. In particular, a statistically significant correlation was found with the presence of bone metastases
$(P=0.04)$ and liver metastases $(P=0.03)$ at the time of observation. At variance, serum Ca 19.9 positivity was not associated with the presence of any type of local or distant metastases at the time of diagnosis (data not shown).

In Table 3, some of the clinical and biochemical features of Ca 19.9-positive patients are summarized.

\section{Serum levels of Ca 19.9 as marker of mortality}

In the group of MTC patients with abnormal serum Ca 19.9 levels $(n=16), 11$ (68.7\%) died from the disease, while only $20(23.8 \%)$ died in the group of MTC patients with normal levels of this marker $(n=84)$. As shown in Fig. 2, the mortality rate was significantly higher $(P=0.0004)$ in the group with higher levels of Ca 19.9 than it was in the group with normal levels of this marker (the sensitivity and specificity of the test were 34 and 93\%, respectively). As shown in Fig. 3, the mortality rate of MTC patients with abnormal levels of serum Ca 19.9 was significantly higher than that of MTC patients with normal levels of this serum marker (mean: $13.1+10.2$ years vs $25.2+8.9$ years; median: 12 years vs 35 years; range $1-19$ years vs $12-35$ years respectively, $P<0.001)$. The mean time from Ca 19.9 measurement and death in the group with Ca 19.9 positivity was 6.3 months (range: 0.5-22 months; median: 4 months).

As far as the correlation with the Ct Dt and mortality is concerned, we found, as expected, a significantly higher rate of death patients $(6 / 6: 100 \%)$ in the group with Ct Dt $<6$ months than in the group with Ct Dt $>6$ months (25/94: 26\%; $P=0.0002)$.

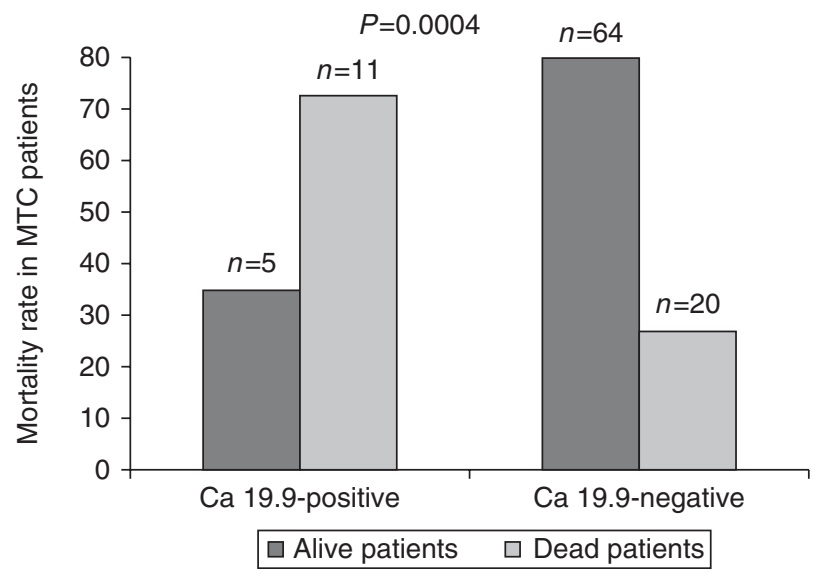

\section{Figure 2}

Mortality rate of patients with abnormal and normal levels of $\mathrm{Ca}$ 19.9: a statistically significant higher percentage of death was observed in the group with abnormal levels of serum Ca 19.9. 


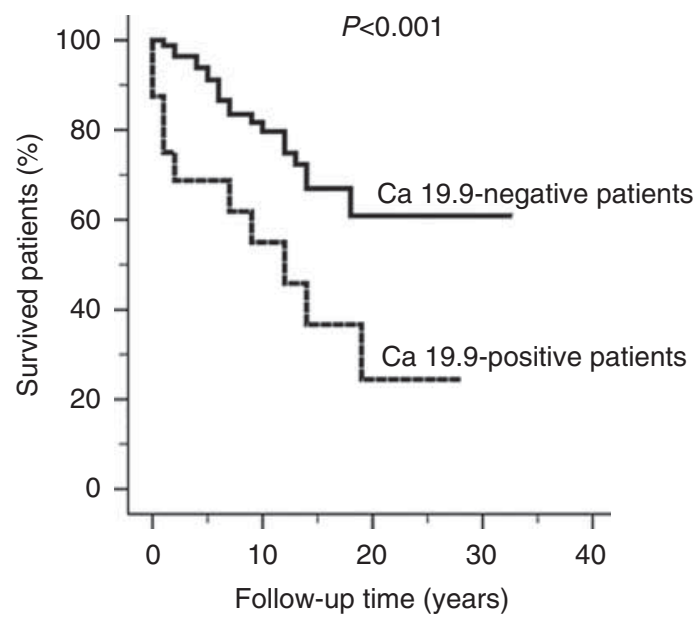

\section{Figure 3}

The Kaplan-Meier curve of survival in patients with normal and abnormal levels of Ca 19.9.

Since both serum Ca 19.9 and Ct Dt were statistically significantly correlated with the rate of mortality, we performed a logistic regression analysis that demonstrated that $\mathrm{Ca} 19.9$ positivity is an important predictor for mortality $(\mathrm{OR}=3.78, P=0.04)$ independent from $\mathrm{Ct} \mathrm{Dt}$ (Table 4).

\section{RET status}

Seventeen of the 100 studied patients (17\%) showed a $R E T$ germline mutation (C618R, C634F, L790P, M918T, A883T, L790F, V871I and Y791F in eight cases; C634R in three cases; C634Y in three cases; V804M in two cases and E768D in another two cases) and were classified as hereditary MTC. Tumoral tissue was available in 57 sporadic cases and RET somatic mutations were found in $73.6 \%$ of the cases. The M918T RET mutation was identified in 36 MTC tissues; in the remaining somatic RET positive cases, we found two mutations at codon 634 , one mutation at codon 883 , one heterozygous $48 \mathrm{bp}$ in frame deletion in exon 10 and two cases with 6 bp in frame deletion in exon 11. In the present series, the presence of a somatic RET mutation did not correlate neither with the levels of the serum Ca 19.9 nor with the mortality of these patients.

\section{Ca 19.9 immunohistochemistry}

Ca 19.9 immunohistochemistry (IHC) was performed on 55 archival formalin-fixed and paraffin-embedded specimens (13 with elevated and 42 with normal serum Ca 19.9 levels).

A positive cytoplasmic staining was found in $84.6 \%$ of the patients with elevated serum Ca 19.9 levels but only in $26.2 \%$ patients with normal serum Ca 19.9 levels $(P=0.0002)$. Some examples of positive cases are represented in Fig. 4.

In particular, we found a statistically significant correlation between the positivity of $\mathrm{Ca} 19.9$ IHC and higher levels of serum Ca.19.9 $(P=0.0002)$. The correlation remained statistically significant also when the degree of positivity of Ca 19.9 IHC was analyzed by three categories $(+,++,+++)(P=0.0012)$.

\section{Discussion}

Recently we observed a peculiar case of aggressive MTC in a young patient with MEN2A who rapidly died of neoplasia (23). High serum levels of $\mathrm{Ca} \mathrm{19.9,} \mathrm{which} \mathrm{is}$ typically considered a gastrointestinal tumor marker (26), were present. Another case of very aggressive MTC associated with high levels of Ca 19.9 was also reported in the literature (22).

Therefore, based on these observations, we conducted the present study to verify whether serum Ca 19.9 levels act as a predictive factor of poor prognosis in the follow-up of MTC patients; in particular, we wondered whether the Ca 19.9 can allow the identification of a subgroup of patients with a higher risk of mortality in the short term.

Very important information about MTC patients' disease status and outcome can be derived from $\mathrm{Ct}$ and CEA levels; in particular, the values of these markers correlate with the tumor burden and, with a few exceptions in which the dedifferentiation of the tumoral cells determines a reduction of $\mathrm{Ct}$ secretion, higher values of serum Ct and CEA are suggestive of the presence of distant metastases (27). In our group of selected advanced/metastatic MTC patients, we found that the values of $\mathrm{Ct}$ and CEA were significantly correlated with serum levels of Ca 19.9, thus suggesting that Ca 19.9 is also dependent on the tumoral mass. In agreement with this finding is the

Table 4 Multivariate analysis (Cox regression model) showing that Ca 19.9 positivity is an important predictor for mortality (OR $=3.78, P=0.04$ ) independent from Ct Dt.

\begin{tabular}{|c|c|c|c|}
\hline $\begin{array}{l}\text { Predictor for } \\
\text { mortality }\end{array}$ & Odds ratio & $P$ value & $95 \% \mathrm{Cl}$ \\
\hline Ca 19.9 & 3.78 & 0.04 & $1.04-13.7$ \\
\hline Ct Dt & 0.00 & 0.99 & $0.0-0.0$ \\
\hline
\end{tabular}


A

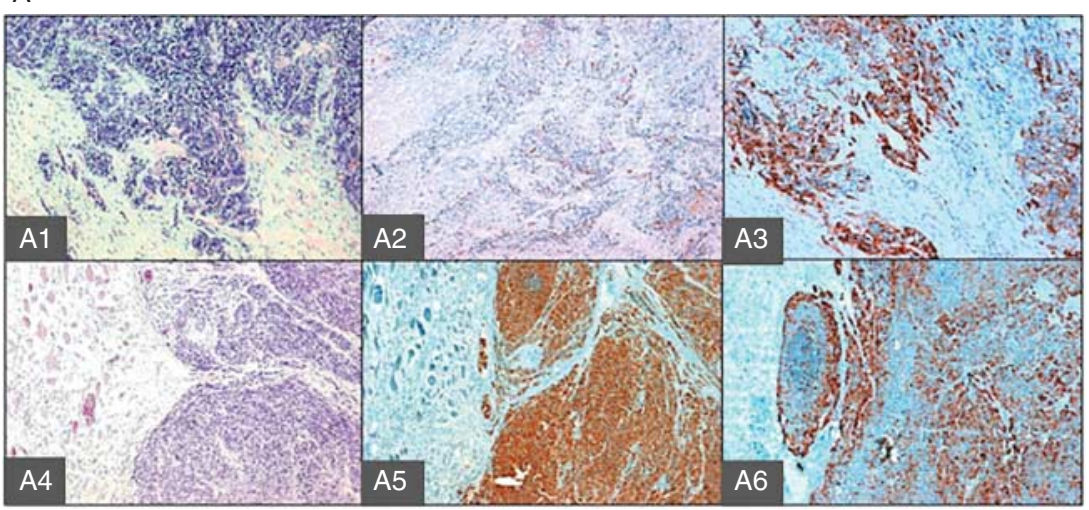

B

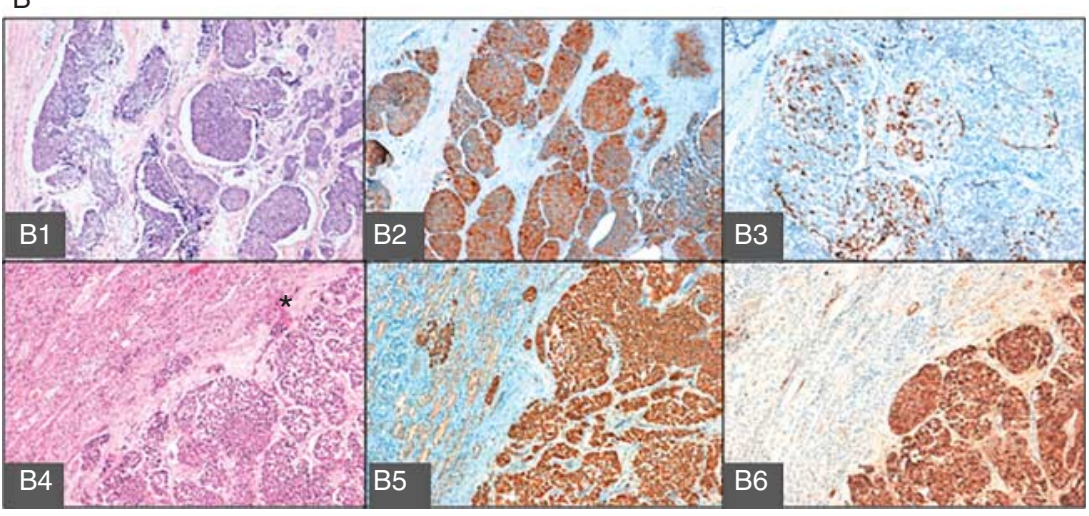

\section{Figure 4}

(A) A representative case of $\operatorname{MTC}(A 1, A 2$ and $A 3)$ with lymph node metastases ( $A 4, A 5$, and $A 6) ; A 1$, haematoxylin-eosin stained section, $10 \times ; A 2$, anti-Ct immunostaining shows focal and weak immunoreactivity of the neoplastic cells, 10X; A3, anti-Ca19.9 immunostaining shows strong cytoplasmatic immunoreactivity of the neoplastic cells, 10X; A4, haematoxylin-eosin stained section shows a complete lymph node metastasis with extension to the skeleton muscle, 10×; A5, A6, anti-Ct and anti-Ca 19.9 immunostaining shows strong and diffuse cytoplasmatic immunoreactivity in metastatic lesion,

evidence that neither cured MTC patients nor those with a persistent biochemical disease (i.e., no evidence of structural disease) showed elevated Ca 19.9 values.

A rapid increase of the Ct and CEA Dt is considered a strong prognostic indicator for MTC recurrence and death, as demonstrated in several studies and metanalyses $(16,17,18)$. This study showed that in our group of advanced MTC, not only the Ct Dt but also abnormal serum levels of Ca 19.9 were prognostic factors of death. Moreover, the multivariate analysis demonstrated that an abnormal level of serum Ca 19.9 was an important predictor of mortality independent from Ct Dt.
$10 \times$; (B) mediastinal lymph node metastasis (B1, B2, and B3) and renal metastasis of $\mathrm{MTC}(\mathrm{B} 4, \mathrm{~B} 5$ and $\mathrm{B} 6) ; \mathrm{B} 1$, haematoxylineosin stained section, $10 \times$; B2, anti-Ct immunostaining, $10 \times$; B3, anti-Ca 19.9 immunostaining shows weak and focal immunoreactivity of the neoplastic cells, $10 \times$; B4, haematoxylin-eosin stained section shows metastatic localization in renal parenchyma (*, renal glomerulus), $10 \times$; $\mathrm{B} 5$ and $\mathrm{B} 6$, anti-Ct and anti-Ca 19.9 immunostaining shows strong and diffuse immunoreactivity of the neoplastic cells, $10 \times$.

The Kaplan-Meier survival curves demonstrated that $<30 \%$ of advanced MTC patients with abnormal Ca 19.9 levels were still alive 20 years after diagnosis, in contrast to the group of advanced MTC patients with normal values of Ca 19.9 , of which $\sim 60 \%$ were still alive. One criticism of our statistical analysis of the relationship between Ca 19.9 values and survival is that we only used one sample collected when the disease was already advanced and we do not know the exact time when patients became positive for this marker. It is conceivable that those cases that were positive for Ca 19.9 at the time of our observation would not be positive at the time of diagnosis but likely intended 
to become positive over the years. The higher prevalence of positivity of Ca 19.9 at IHC in the group of patients with positive levels of serum Ca 19.9 and the finding that all of the MTC patients without structural disease showed normal levels of Ca 19.9 can support our hypothesis. It would be of interest to follow up those cases that were positive at IHC, but with still normal levels of Ca 19.9 at our observation, to verify if they will become positive for this marker. To have more precise information about the prognostic role of $\mathrm{Ca} 19.9$, a prospective study that includes collecting serum samples for the $\mathrm{Ca} 19.9$ measurement is now ongoing in our center.

It is known that MTC are tumors able to produce and secrete several antigens (19). Until a few weeks ago, only one study reported that $6 \%$ of MTC is able to produce Ca 19.9 at tissue level (21). Very recently, ten out of 16 MTC cases were demonstrated to be stained positive for $\mathrm{Ca} 19.9$ and to be associated with metastatic spread of disease (28). In our selected series of advanced/metastatic MTC tissues, $40 \%$ of the cases were positive by IHC, and the majority of the cases had abnormal levels of serum Ca 19.9. The above-mentioned prospective study will include the IHC analysis on the primary tumor to verify if the tissue presence of Ca 19.9 will allow to identify those MTC cases who will also become positive at serum level over the years and thus be at a higher risk of death.

A further objective of the study was to correlate the Ca 19.9 positivity with some clinical and pathological features of the tumor. The only statistical difference between the two groups was that distant metastases, particularly bone and liver metastases, which are known to be a poor prognostic factor for survival $(7,8,9,29)$, were much more frequent in patients with elevated levels of Ca 19.9 at the time of observation. However, in the present selected series, the distant metastases did not correlate with death while it did occur for Ca 19.9, suggesting a stronger prognostic role of this serum marker in this subset of advanced cases.

We know that the presence of RET somatic mutations correlates with an advanced stage at the time of diagnosis and a lower survival rate $(11,12,13)$. In the present series, the RET somatic mutations did not correlate with the death of these patients. It is conceivable that this finding was due to the unbalanced proportion between negative and positive RET cases, which likely determines a problem of statistical power. Unfortunately, this is an unavoidable bias because in this series of selected advanced MTC cases the prevalence of RET somatic mutations is high (73.6\%) with respect to that usually reported (about $43 \%$ ) in unselected series or in smaller MTC $(11,30,31)$. As far as the absence of a correlation between Ca 19.9 positivity and RET mutations is concerned, we can hypothesize that cases with elevated levels of Ca 19.9 represent a subgroup of advanced RETpositive MTC patients with a higher probability of death. As matter of fact, we previously showed that only $18.6 \%$ of $R E T$-positive MTC patients had a survival time of $<10$ years (11), thus implying that other risk factors interfering with the survival of these patients are also present. We can hypothesize that the positivity of Ca 19.9 is an indicator of the presence of such other risk factors.

In conclusion, we demonstrated that abnormal levels of Ca 19.9 are present in $40 \%$ of advanced/metastatic MTC tissues and in $16 \%$ of sera from the same group of patients. The serum Ca 19.9 positivity identifies a subgroup of advanced/metastatic MTC with higher levels of serum Ct and CEA and also a short Ct Dt who have a higher risk of death from the disease in the short term. A prospective study is underway to verify whether the early identification of Ca 19.9-positive MTC cases will allow the identification of higher-risk patients who may require more stringent follow-up and instant systemic therapy.

\section{Declaration of interest}

The authors declare that there is no conflict of interest that could be perceived as prejudicing the impartiality of the research reported.

\section{Funding}

This study was supported in part by grants from the Associazione Italiana per la Ricerca sul Cancro (AIRC), investigator grant 15431, and the Istituto Toscano Tumori (ITT).

\section{References}

1 Marsh DJ, Learoyd DL \& Robinson BG. Medullary thyroid carcinoma: recent advances and management update. Thyroid 19955 407-424. (doi:10.1089/thy.1995.5.407)

2 Griebeler ML, Gharib H \& Thompson GB. Medullary thyroid carcinoma. Endocrine Practice 201319 703-711. (doi:10.4158/ EP12430.RA)

3 Wells SA Jr, Asa SL, Dralle H, Elisei R, Evans DB, Gagel RF, Lee NY, Machens A, Moley JF, Pacini F et al. Revised american thyroid association guidelines for the management of medullary thyroid carcinoma the american thyroid association guidelines task force on medullary thyroid carcinoma. Thyroid 201525 567-610. (doi:10.1089/ thy.2014.0335)

4 Romei C, Pardi E, Cetani F \& Elisei R. Genetic and clinical features of multiple endocrine neoplasia types 1 and 2. Journal of Oncology 2012 2012 705036. (doi:10.1155/2012/705036)

5 Eng C. Multiple endocrine neoplasia type 2 and the practice of molecular medicine. Reviews in Endocrine \& Metabolic Disorders 20001 283-290. (doi:10.1023/A:1026514301172)

6 Hyer SL, Vini L, A'Hern R \& Harmer C. Medullary thyroid cancer: multivariate analysis of prognostic factors influencing survival. 
European Journal of Surgical Oncology 200026 686-690. (doi:10.1053/ ejso.2000.0981)

7 Gharib H, McConahey WM, Tiegs RD, Bergstralh EJ, Goellner JR, Grant CS, van Heerden JA, Sizemore GW \& Hay ID. Medullary thyroid carcinoma: clinicopathologic features and long-term follow-up of 65 patients treated during 1946 through 1970. Mayo Clinic Proceedings 1992 67 934-940. (doi:10.1016/S0025-6196(12)60923-9)

8 Machens A \& Dralle H. Prognostic impact of N staging in 715 medullary thyroid cancer patients: proposal for a revised staging system. Annals of Surgery 2013257 323-329. (doi:10.1097/SLA.0b013e318268301d)

9 Rios A, Rodriguez JM, Acosta JM, Balsalobre MD, Torregrosa N, Sola J, Perez-Flores D \& Parrilla P. Prognostic value of histological and immunohistochemical characteristics for predicting the recurrence of medullary thyroid carcinoma. Annals of Surgical Oncology 201017 2444-2451. (doi:10.1245/s10434-010-1021-4)

10 Zedenius J, Larsson C, Bergholm U, Bovee J, Svensson A, Hallengren B, Grimelius L, Backdahl M, Weber G \& Wallin G. Mutations of codon 918 in the RET proto-oncogene correlate to poor prognosis in sporadic medullary thyroid carcinomas. Journal of Clinical Endocrinology and Metabolism 199580 3088-3090.

11 Elisei R, Cosci B, Romei C, Bottici V, Renzini G, Molinaro E, Agate L, Vivaldi A, Faviana P, Basolo F et al. Prognostic significance of somatic RET oncogene mutations in sporadic medullary thyroid cancer: a 10-year follow-up study. Journal of Clinical Endocrinology and Metabolism 200893 682-687. (doi:10.1210/jc.2007-1714)

12 Mian C, Pennelli G, Barollo S, Cavedon E, Nacamulli D, Vianello F, Negro I, Pozza G, Boschin IM, Pelizzo MR et al. Combined RET and Ki-67 assessment in sporadic medullary thyroid carcinoma: a useful tool for patient risk stratification. European Journal of Endocrinology/ European Federation of Endocrine Societies 2011164 971-976. (doi:10.1530/EJE-11-0079)

13 Moura MM, Cavaco BM, Pinto AE, Domingues R, Santos JR, Cid MO, Bugalho MJ \& Leite V. Correlation of RET somatic mutations with clinicopathological features in sporadic medullary thyroid carcinomas. British Journal of Cancer 2009100 1777-1783. (doi:10.1038/sj.bjc.6605056)

14 DeLellis RA, Rule AH, Spiler I, Nathanson L, Tashjian AH Jr \& Wolfe HJ. Calcitonin and carcinoembryonic antigen as tumor markers in medullary thyroid carcinoma. American Journal of Clinical Pathology 197870 587-594.

15 Barbet J, Campion L, Kraeber-Bodere F \& Chatal JF. Prognostic impact of serum calcitonin and carcinoembryonic antigen doubling-times in patients with medullary thyroid carcinoma. Journal of Clinical Endocrinology and Metabolism 200590 6077-6084. (doi:10.1210/ jc.2005-0044)

16 Meijer JA, le Cessie S, van den Hout WB, Kievit J, Schoones JW, Romijn JA \& Smit JW. Calcitonin and carcinoembryonic antigen doubling times as prognostic factors in medullary thyroid carcinoma: a structured meta-analysis. Clinical Endocrinology 201072 534-542. (doi:10.1111/j.1365-2265.2009.03666.x)

17 Gawlik T, d'Amico A, Szpak-Ulczok S, Skoczylas A, Gubala E, Chorazy A, Gorczewski K, Wloch J \& Jarzab B. The prognostic value of tumor markers doubling times in medullary thyroid carcinoma - preliminary report. Thyroid Research 20103 10. (doi:10.1186/1756-6614-3-10)

18 Laure Giraudet A, Al Ghulzan A, Auperin A, Leboulleux S, Chehboun A, Troalen F, Dromain C, Lumbroso J, Baudin E \& Schlumberger M. Progression of medullary thyroid carcinoma: assessment with calcitonin and carcinoembryonic antigen doubling times. European Journal of Endocrinology/European Federation of Endocrine Societies 2008 158 239-246. (doi:10.1530/EJE-07-0667)

19 Pacini F, Basolo F, Elisei R, Fugazzola L, Cola A \& Pinchera A. Medullary thyroid cancer. An immunohistochemical and humoral study using six separate antigens. American Journal of Clinical Pathology 199195 300-308.

20 Pacini F, Elisei R, Anelli S, Basolo F, Cola A \& Pinchera A. Somatostatin in medullary thyroid cancer. In vitro and in vivo studies. Cancer 198963 1189-1195. (doi:10.1002/1097-0142(19890315)63:6<1189::AIDCNCR2820630625>3.0.CO;2-J)

21 Larena A, Vierbuchen M \& Fischer R. Blood group antigen expression in malignant tumors of the thyroid: a parallel between medullary and nonmedullary carcinomas. Langenbecks Archiv für Chirurgie 1995380 269-272.

22 Milman S, Whitney KD \& Fleischer N. Metastatic medullary thyroid cancer presenting with elevated levels of CA 19-9 and CA 125. Thyroid 201121 913-916. (doi:10.1089/thy.2010.0425)

23 Elisei R, Lorusso L, Romei C, Bottici V, Mazzeo S, Giani C, Fiore E, Torregrossa L, Insilla AC, Basolo F et al. Medullary thyroid cancer secreting carbohydrate antigen 19-9 (Ca 19-9): a fatal case report. Journal of Clinical Endocrinology and Metabolism 201398 3550-3554. (doi:10.1210/jc.2013-1940)

24 Kloos RT, Eng C, Evans DB, Francis GL, Gagel RF, Gharib H, Moley JF, Pacini F, Ringel MD, Schlumberger $\mathrm{M}$ et al. Medullary thyroid cancer: management guidelines of the American Thyroid Association. Thyroid 200919 565-612. (doi:10.1089/thy.2008.0403)

25 Romei C, Cosci B, Renzini G, Bottici V, Molinaro E, Agate L, Passannanti P, Viola D, Biagini A, Basolo F et al. RET genetic screening of sporadic medullary thyroid cancer (MTC) allows the preclinical diagnosis of unsuspected gene carriers and the identification of a relevant percentage of hidden familial MTC (FMTC). Clinical Endocrinology 201174 241-247. (doi:10.1111/j.1365-2265.2010.03900.x)

26 Duffy MJ, Sturgeon C, Lamerz R, Haglund C, Holubec VL, Klapdor R, Nicolini A, Topolcan O \& Heinemann V. Tumor markers in pancreatic cancer: a European Group on Tumor Markers (EGTM) status report. Annals of Oncology 201021 441-447. (doi:10.1093/annonc/mdp332)

27 Machens A \& Dralle H. Biomarker-based risk stratification for previously untreated medullary thyroid cancer. Journal of Clinical Endocrinology and Metabolism 201095 2655-2663. (doi:10.1210/ jc.2009-2368

28 Milman S, Arnold JL, Price M, Negassa A, Surks MI, Fleischer N \& Whitney KD. Medullary thyroid cancer that stains negative for CA 19-9 has decreased metastatic potential. Endocrine Practice 201521 590-594. (doi:10.4158/EP14357.OR)

29 Wu K, Hou SM, Huang TS \& Yang RS. Thyroid carcinoma with bone metastases: a prognostic factor study. Clinical Medicine. Oncology 20082 129-134.

30 Ciampi R, Mian C, Fugazzola L, Cosci B, Romei C, Barollo S, Cirello V, Bottici V, Marconcini G, Rosa PM et al. Evidence of a low prevalence of RAS mutations in a large medullary thyroid cancer series. Thyroid 2013 23 50-57. (doi:10.1089/thy.2012.0207)

31 Romei C, Ugolini C, Cosci B, Torregrossa L, Vivaldi A, Ciampi R, Tacito A, Basolo F, Materazzi G, Miccoli P et al. Low prevalence of the somatic M918T RET mutation in micro-medullary thyroid cancer. Thyroid 201222 476-481. (doi:10.1089/thy.2011.0358)
Received 18 March 2015

Revised version received 6 May 2015

Accepted 1 June 2015 